\title{
CORRECTION
}

\section{Correction to: Cure kinetic study of methacrylate-POSS copolymers for ocular Lens}

\author{
F. Shokrolahi ${ }^{1} \cdot$ M. Zandi ${ }^{1} \cdot$ P. Shokrollahi ${ }^{1} \cdot$ M. Atai ${ }^{2} \cdot$ E. Gafar-Zadeh ${ }^{3} \cdot$ M. Hanifeh $^{1}$
}

Published online: 23 January 2018

(c) The Author(s) 2018. This article is an open access publication

\section{Correction to: Prog Biomater (2017) 6:147-156 https://doi.org/10.1007/s40204-017-0074-x}

The original version of this article unfortunately contained a mistake: the spelling of the Ebrahim Gafar-Zadehs' name was incorrect. The corrected name is given above.

Open Access This article is distributed under the terms of the Creative Commons Attribution 4.0 International License (http://creativecommons.org/licenses/by/4.0/), which permits unrestricted use, distribution, and reproduction in any medium, provided you give appropriate credit to the original author(s) and the source, provide a link to the Creative Commons license, and indicate if changes were made.

The original article can be found online at https://doi.org/10.1007/ s40204-017-0074-x.

M. Zandi

m.zandi@ippi.ac.ir

1 Biomaterials Department, Iran Polymer and Petrochemical Institute, Pazhoohesh Blvd, Tehran-Karaj Hwy, 1497713115 Tehran, Iran

2 Science Department, Iran Polymer and Petrochemical Institute, Pazhoohesh Blvd, Tehran-Karaj Hwy, 1497713115 Tehran, Iran

3 Lassonde School of Engineering, York University, 4700 Keele Street, 11 Arboretum Ln, ON M3J 1P3 Toronto, Canada 